\title{
A clinical report demonstrating the significance of distinguishing a nasopalatine duct cyst from a radicular cyst
}

\author{
Manikkath Aparna, ${ }^{1}$ Arumugam Chakravarthy, ${ }^{2}$ Shashi Rashmi Acharya, ${ }^{2}$ \\ Raghu Radhakrishnan ${ }^{1}$
}

${ }^{1}$ Department of Oral Pathology and Microbiology, Manipal College of Dental Sciences, Manipal, Karnataka, India ${ }^{2}$ Department of Operative Dentistry and Endodontics, Manipal College of Dental Sciences, Manipal, Karnataka, India

\section{Correspondence to} Professor Raghu Radhakrishnan, raghu. radhakrishnan@gmail.com

Accepted 24 February 2014

\section{CrossMark}

To cite: Aparna M,
Chakravarthy A, Acharya SR,
et al. BMJ Case Rep
Published online: [please
include Day Month Year]
doi:10.1136/bcr-2013-
200329

\begin{abstract}
SUMMARY
Endodontic diagnosis is challenging and depends on the organisation of information from the patient history, clinical examination and analysis of the pulp, radiographic and histopathological assessment. A 35year-old man was endodontically treated for radiolucency in relation to the roots of maxillary central incisors as it was a provisionally diagnosed case of radicular cyst. Since the palatal swelling persisted, the lesion was reevaluated using relevant diagnostic aids and a diagnosis of nasopalatine duct cyst (NPDC) was made, which was missed during the initial assessment. An erroneous interpretation of cystic radiolucency in relation to maxillary central incisors can often lead to inappropriate treatment planning. This case highlights the relevant aspects in the diagnosis of NPDC when it is mistaken for a radicular cyst and emphasises the need for thorough clinical examination and relevant investigations for periapical radiolucencies of questionable origin before initiating endodontic therapy.
\end{abstract}

\section{BACKGROUND}

The nasopalatine duct cyst (NPDC) is the most common non-odontogenic cyst of the oral cavity constituting about $1.7-11.9 \%$ of all jaw cysts. Most cases occur in the fourth to sixth decade ${ }^{1}$ and men are affected three times more commonly than women. ${ }^{2}$ These arise within the incisive canals of the palatine bone behind the alveolar processes of the central incisors or in the palatal soft tissue at the openings of the canals. Several terms have been used to depict this entity such as 'median anterior cyst', 'midline maxillary cyst', 'anterior median palatine cyst' and 'incisive canal cyst'. ${ }^{1}$

The NPDC originates from the proliferating epithelial remnants of nasopalatine duct. It is attributed to a number of causes such as infection, retention phenomenon of the blocked mucous glands, epithelial remnants of the Jacobson's organ, trauma, ill-fitting dentures or idiopathic. ${ }^{1}$ Owing to its location NPDC is often mistaken for several other pathological entities which may occur in this region such as a large incisive fossa, radicular cyst, dentigerous cyst arising from a mesiodens, oronasal fistula, oroantral fistula, chronic draining dentoalveolar abscess with sinus tract. ${ }^{3}$ The clinical implications and the treatment options vary depending on the nature of each of these entities necessitating the importance of accurate diagnosis. This article presents a case of NPDC, which was inadvertently managed by root canal treatment following an erroneous diagnosis of a radicular cyst in relation to the maxillary central incisors.

\section{CASE PRESENTATION}

A 35-year-old man presented with a painless swelling in the palate in relation to the maxillary central incisors. The swelling was initially noticed about 6 months previously. There was no history of trauma, or mobility of the associated teeth. A mucoid discharge drained out from it infrequently. Considering it to be an infected dental cyst, endodontic treatment was initiated. However, the swelling showed no signs of regression following which the patient was referred to the university hospital for treatment. The swelling was soft, fluctuant and measured $1 \times 0.5 \mathrm{~cm}$.

\section{INVESTIGATIONS}

Radiographs revealed a well-defined radiolucency between the roots of the maxillary central incisors without any evidence of root resorption. It was also apparent during radiographic examination that the first stage of endodontic procedure had been carried out in relation to the same teeth (figure 1).

\section{DIFFERENTIAL DIAGNOSIS}

Radicular cyst, NPDC, nasoalveolar cyst, central giant cell granuloma and wide incisive canal were considered in the differential diagnosis.

\section{TREATMENT}

The first-line of patient management included surgical enucleation of the lesion and completion of endodontic treatment. Calcium hydroxide was used as the intracanal medicament. The enucleated tissue was submitted for microscopic examination.

\section{OUTCOME AND FOLLOW-UP}

Microscopic examination revealed a cystic lumen lined by pseudostratified columnar epithelium to stratified squamous non-keratinised epithelium. The underlying connective tissue capsule was fibrous with numerous blood vessels, haemorrhagic areas and sparse inflammatory cells. Focal aggregates of rounded calcific material were found dispersed in the connective tissue capsule (figure 2). The lesion was signed out as NPDC.

The review radiograph that was taken 18 months after the surgical procedure showed areas of radiopacity within the radiolucent defect suggestive of healing (figure 3 ). 


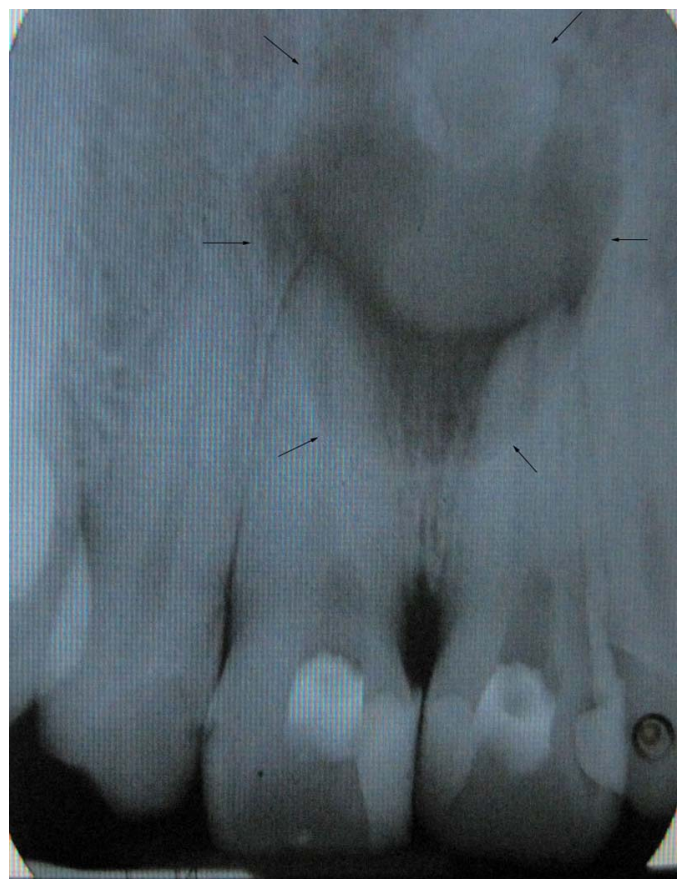

Figure 1 Intraoral periapical radiograph showing well-defined round radiolucency in between the roots of the maxillary central incisors.

\section{DISCUSSION}

The diagnosis and management of periapical radiolucency is intriguing and equally challenging. It requires meticulous recording of clinical history, pulp testing, assessment of crucial radiographic evidence, and critical histological correlation of the lesion in question before therapeutic intervention. In the present case, there was no history of trauma or infection. In this setting it is fundamental to determine the vitality of the incisors by pulp testing which was not carried out. Furthermore it is quite unusual for a radicular cyst in the maxillary incisor region to present with a palatal swelling. The management of the lesion by endodontic procedure was based solely on the radiographic presentation of a well-defined cystic lesion in relation to

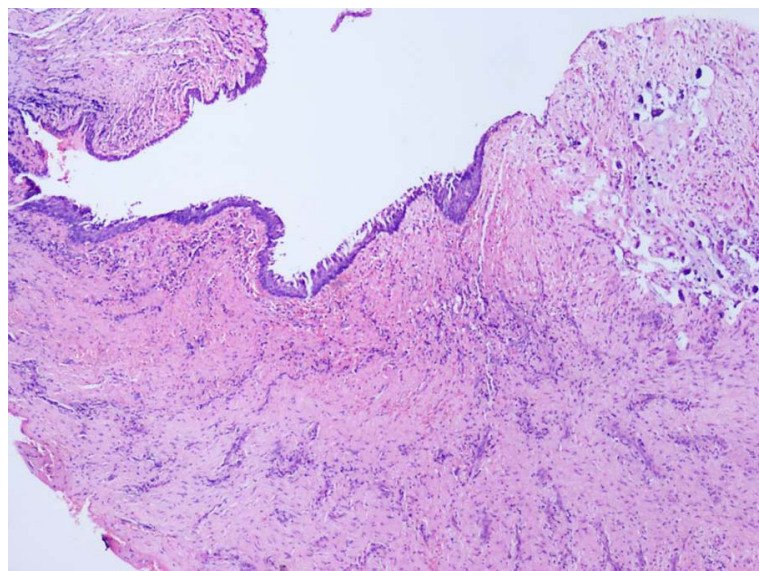

Figure 2 Photomicrograph showing a cystic lumen lined by stratified squamous epithelium (A) and pseudostratified (B) at places. The connective tissue capsule shows numerous blood vessels and haemorrhagic areas admixed with a diffuse infiltration of chronic inflammatory cells chiefly the lymphocytes and plasma cells (C). Areas of calcific deposits are also seen (D; H\&E, $\times 20$ ). the roots of the maxillary central incisors pre-empting the lesion to be of dental origin. As the swelling did not regress following initial treatment, the patient had been referred to the University Hospital for opinion. Subsequent intervention and surgical therapeutic protocol confirmed that the cystic lesion was NPDC.

The most striking feature, which confirmed the diagnosis of NPDC, was the presence of a cystic lining which varied from stratified squamous to pseudostratified ciliated columnar epithelium. These features as well as the presence of a highly vascular connective tissue capsule led us to the diagnosis of NPDC. It has been suggested that the reasons for this epithelial diversity are the proximity of the lesion to the nasal cavity and the pluripotentiality of the embryonic epithelial remnants. ${ }^{1}{ }^{4}$ Calcific deposits noticed were thought to be due to the extrusion of calcium hydroxide used as the intracanal medicament in the course of endodontic therapy. Calcium hydroxide has been shown to be very well tolerated by periapical tissues ${ }^{5}$ and hence does not elicit any significant inflammatory response.

It is essential to distinguish these cysts from a radicular cyst, and a wide incisive canal. A radicular cyst is usually associated with non-vital teeth and generally involves the roots of teeth with loss of continuity of the lamina dura. In contrast, the NPDC is typically associated with vital teeth. These cysts can be well-circumscribed, ovoid, round, pear or heart-shaped radiolucent areas located in between the roots of the maxillary central incisors ${ }^{1}$ with the continuity of the lamina dura generally maintained. ${ }^{2}$ Furthermore altering the horizontal angulation of a periapical radiograph changes the position of the image of the NPDC while the radicular cyst maintains its position around the apex of the central incisor. ${ }^{67}$ Distinction of NPDC from a large incisive fossa can be made clinically by aspiration of the lesion. A radiolucency of $0.6-0.8 \mathrm{~cm}$ in this location, with ill-defined borders is regarded as a large incisive fossa. ${ }^{1}$ Cysts generally present as spherical radiolucencies and tend to have well-defined margins with the superior margin at a higher level as compared with that of an incisive fossa. ${ }^{4}$

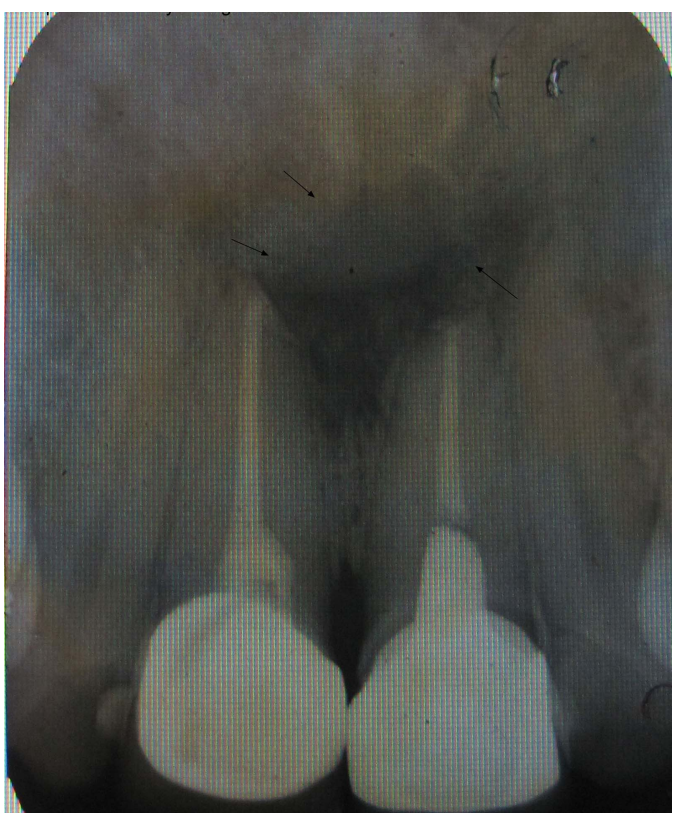

Figure 3 An 18-month postoperative radiograph showing adequate healing and bone formation. 
Table 1 Reported cases of nasopalatine duct cyst initially misdiagnosed as a radicular cyst

\begin{tabular}{|c|c|c|c|c|}
\hline SI. No. & Reference & $\begin{array}{l}\text { Number of } \\
\text { Cases }\end{array}$ & $\begin{array}{l}\text { Age in years/ } \\
\text { sex }\end{array}$ & Radiographic features \\
\hline 1 & Allard et al ${ }^{1}$ & 1 & NS & NS \\
\hline 2 & Gnanasekhar et al ${ }^{2}$ & 1 & $42 / \mathrm{M}$ & Well-circumscribed ovoid radiolucent area between the roots of the vital maxillary central incisors \\
\hline 3 & Kuc et $a l^{8}$ & 2 & NS & NS \\
\hline 6 & Ortega et $a l^{9}$ & 1 & NS & NS \\
\hline 3 & Terry and Bolanos ${ }^{11}$ & 1 & $40 / \mathrm{F}$ & Heart-shaped radiolucency with a sclerotic border in between the maxillary right central incisors \\
\hline 4 & $\begin{array}{l}\text { Gulabivala and } \\
\text { Briggs }^{12}\end{array}$ & 1 & NS & NS \\
\hline 7 & Faitaroni et $a l^{13}$ & 2 & $\begin{array}{l}49 / \mathrm{M} \\
28 / \mathrm{M}\end{array}$ & Root canal filling and periapical radiolucency \\
\hline 8 & Suter et al ${ }^{14}$ & 2 & $\begin{array}{l}17 / M \\
42 / M\end{array}$ & $\begin{array}{l}\text { Radiolucency extending from the upper left to the upper right canine region and including the } \\
\text { nasal cavity }\end{array}$ \\
\hline 9 & Our case & 1 & $35 / \mathrm{M}$ & Well-defined, round radiolucency in between the roots of the maxillary central incisors \\
\hline
\end{tabular}

Majority of the periapical lesions including pulpal abscess, granulomas and cysts are a sequence of pulpal necrosis, most of which can be successfully treated by conservative endodontic therapy. However, there are numerous other lesions that occur in this region including developmental cysts, infections and malignancies without any relationship to the pulpal status and therefore do not resolve after endodontic intervention. These require diverse modalities of treatment and their true nature can be confirmed solely by means of histological evaluation. In a study of 805 periapical biopsy specimens, Kuc et $a l^{8}$ concluded that a histopathological examination contributed clinically relevant information in 5\% of cases. Similarly Ortega et al $l^{9}$ studied the frequency with which histological diagnosis of periapical lesions changed the clinical opinion. It was found that among the cases which were clinically diagnosed as periapical pathology, $0.65 \%$ was found to have a non-endodontic origin after microscopic assessment. These facts emphasise the importance of microscopic evaluation of all excised tissues, especially those with inadequate history or unusual radiographic image. The management of NPDC is fairly simple. Complete curettage or surgical enucleation has been the treatment of choice. The recurrence rate is low. ${ }^{10}$

There are a few reports cited in literature where NPDC has been mistakenly diagnosed as radicular cyst (table 1). ${ }^{1} 28911-14$

In conclusion, we describe a case of NPDC that was erroneously diagnosed as a radicular cyst which led to an inadvertent endodontic therapy. Although periapical pathologies appear to be quite unambiguous in presentation, considerable prudence has to be exercised by the clinician in delivering appropriate therapy. Thus an appropriate interpretation of clinical, radiographic and histological features offers pertinent clue to the diagnosis of NPDC when it is mistaken for a radicular cyst.

\section{Learning points}

- The case presented here is of interest because of the initial erroneous diagnosis and the redundant endodontic treatment that was carried out.

- Every persistent palatal swelling in the maxillary anterior region has to be submitted for histological evaluation.

- Important criteria to distinguish periapical cyst from the nasopalatine duct cyst have been highlighted.
Contributors SRA and AC were associated with the clinical management of the case. MA was involved in the conception, design and literature search. RR and MA were involved in the drafting of the article and revising it critically for the intellectual content of the manuscript. RR and MA were also involved in the final approval of the version published.

Competing interests None.

Patient consent Obtained.

Provenance and peer review Not commissioned; externally peer reviewed.

\section{REFERENCES}

1 Allard RH, van der Kwast WA, van der Waal I. Nasopalatine duct cyst. Review of the literature and report of 22 cases. Int J Oral Surg 1981;10:447-61.

2 Gnanasekhar JD, Walvekar SV, al-Kandari AM, et al. Misdiagnosis and mismanagement of a nasopalatine duct cyst and its corrective therapy. A case report. Oral Surg Oral Med Oral Pathol Oral Radiol Endod 1995;80:465-70.

3 Moss HD, Hellstein JW, Johnson JD. Endodontic considerations of the nasopalatine duct region. J Endod 2000;26:107-10.

4 Abrams AM, Howell FV, Bullock WK. Nasopalatine cysts. Oral Surg Oral Med Oral Pathol 1963;16:306-32.

5 Binnie WH, Rowe AH. A histological study of the periapical tissues of incompletely formed pulpless teeth filled with calcium hydroxide. J Dent Res 1973;52:1110-16.

6 Hoseini SV, Khiavi MM, Aghbali A, et al. Unilateral nasopalatine duct cyst, differential diagnosis and treatment plan: a case report. Shiraz Univ Dent J 2011;12:95-9.

7 Srivastava S, Misra N, Agarwal R, et al. Nasopalatine canal cyst: often missed. BMJ Case Rep 2013; 2013:pii: bcr2012007548.

8 Kuc I, Peters E, Pan J. Comparison of clinical and histologic diagnoses in periapical lesions. Oral Surg Oral Med Oral Pathol Oral Radiol Endod 2000;89:333-7.

9 Ortega A, Fariña V, Gallardo A, et al. Nonendodontic periapical lesions: a retrospective study in Chile. Int Endod J 2007;40:386-90.

10 Elliott KA, Franzese CB, Pitman KT. Diagnosis and surgical management of nasopalatine duct cysts. Laryngoscope 2004;114:1336-40.

11 Terry BR, Bolanos OR. A diagnostic case involving an incisive canal cyst. J Endod 1989;15:559-62.

12 Gulabivala K, Briggs PF. Diagnostic dilemma: an unusual presentation of an infected nasopalatine duct cyst. Int Endod J 1992;25:107-11.

13 Faitaroni LA, Bueno MR, Carvalhosa AA, et al. Differential diagnosis of apical periodontitis and nasopalatine duct cyst. J Endod 2011;37:403-10.

14 Suter VG, Büttner $M$, Altermatt $H J$, et al. Expansive nasopalatine duct cysts with nasal involvement mimicking apical lesions of endodontic origin: a report of two cases. J Endod 2011;37:1320-6. 
Copyright 2014 BMJ Publishing Group. All rights reserved. For permission to reuse any of this content visit http://group.bmj.com/group/rights-licensing/permissions.

BMJ Case Report Fellows may re-use this article for personal use and teaching without any further permission.

Become a Fellow of BMJ Case Reports today and you can:

- Submit as many cases as you like

- Enjoy fast sympathetic peer review and rapid publication of accepted articles

- Access all the published articles

- Re-use any of the published material for personal use and teaching without further permission

For information on Institutional Fellowships contact consortiasales@bmjgroup.com

Visit casereports.bmj.com for more articles like this and to become a Fellow 